\title{
Relationship between Malaria and ABO Blood Group Types
}

\author{
Running Title: ABO Group and Malaria \\ Sharana Hegde ${ }^{1}$, Ruchi Sinha ${ }^{2}$, Shrijeet Chakraborti ${ }^{3}$, Lavnish Ojha ${ }^{4}$ \\ ${ }^{1}$ MBBS, Department of Pathology, Kasturba Medical College, Manipal University, Mangalore, Karnataka, India \\ ${ }^{2} \mathrm{MD}$, Associate Professor, Department of Pathology \& Laboratory Medicine, All India Institute of Medical Sciences, Patna, India \\ ${ }^{3}$ MD, DNB, PDF-Neuropath, PGDEA, Associate Professor, Department of Pathology, Kasturba Medical College, Manipal University, \\ Mangalore, Karnataka, India \\ ${ }^{4}$ MBBS, Department of Pathology, Kasturba Medical College, Manipal University, Mangalore, Karnataka, India

\begin{abstract}
Introduction: There is a paucity of studies on the relationship between ABO blood group and its influence on malarial infection. This study was undertaken to study the relationship of severity of malaria with blood groups and to evaluate if ABO blood groups show differential susceptibility to falciparummalaria. Methods: In 200 malaria positive patients, blood group analysis was done. Patients with at least one of the following complications was considered complicated malaria cases, ie: cerebral malaria, severe anemia, circulatory collapse, jaundice, hematuria, bleeding manifestations, acute respiratory distress syndrome, and death. Results: Vivax malaria (75.5\%) and blood group $O(43 \%)$ were the commonest amongst the cases. No significant relationship was present between blood groups and type of infection, parasite load vs blood groups, and complicated cases vs parasite load. Uncomplicated (62\%) cases were more than complicated $(31 \%)$ cases. Blood group $O$ dominated among complicated (37.9\%) and uncomplicated (45.65\%) cases. No signifiant correlation was present between blood groups and distribution of complicated cases, and between complicated falciparum cases and blood groups. Seven cases of mixed malaria had blood group A and O. Among A blood group, 57.1\% of the mixed malaria cases had complications, whereas in $O$ blood group only $14.3 \%$ had complications. There was a statistically significant relation between complicated mixed malaria cases and blood groups, with blood group A being more prone to complications. $\left(X^{2}=15.131 ; P=0.019\right)$. Conclusions: Blood group $O$ was the dominant blood type in both complicated and uncomplicated malaria cases. Blood group $A$ cases were more prone to severe mixed malaria infections while, blood group $\mathrm{O}$ had a favorable clinical outcome.
\end{abstract}

Keywords: Blood group, Plasmodium falciparum, Plasmodium vivax, Mixed malaria, Complicated malaria

\section{Introduction}

Malaria is one of the most important parasitic disease affecting humans, with 198 million (uncertainty range 124283 million) malaria cases worldwide leading to 584,000 (uncertainty range $367,000-755,000$ ) deaths ${ }^{(1)}$.

Malaria is caused by an obligate, intracellular protozoan parasite of the genus Plasmodium. Of the five species that can infect humans, P.falciparum $(P f)$ causes more severe forms of the disease. The virulence of $P f$ has been associated with the capacity of the infected red blood cells (RBCs) to adhere to uninfected RBCs, leading to rosetting of cells; thereby causing hemorrhagic complications ${ }^{(2)}$. Blood group antigens $\mathrm{A}$ and $\mathrm{B}$ act as receptors for rosetting on uninfected RBCs and bind to parasite rosetting ligands such as PfEMP-1 and cause sequestering ${ }^{(3)}$.

Malaria cases are less likely to be severe in blood group $\mathrm{O}$ patients, and significantly more severe in blood group AB. It appears that individuals who are of blood group $\mathrm{O}$ are relatively resistant to the severe disease caused by $P f$ infection ${ }^{(4,5)}$.Clinical severity, rather than incidence or prevalence of detectable parasitemia, is a more relevant outcome to assess $\mathrm{ABO}$ group and survival, because parasite density does not always predict survival.

Paucity of studies on the relationship between human ABO blood group and disease severity of malarial infection, prompted us to undertake this study. The relationship of severity of malaria and differential susceptibility to species of malaria with blood groups was studied.

\section{Materials and Methods}

This hospital based prospective, cross-sectional study, was conducted on patients attending the outpatient services or admitted in Kasturba Medical College, Mangalore, India. Informed consent and ethics committee approval were taken. Over a period of two months, 200 malaria positive patients were studied. The sample size was calculated based on the prevalence of malaria. in the area. The criteria for complicated malaria, considered in this study was, any patient having atleast one of the complications: cerebral malaria, severe anemia (hemoglobin $<9 \mathrm{~g} / \mathrm{dl}$ ), circulatory collapse (systolic blood pressure $<80 \mathrm{mmHg}$ in patients $>5$ years of age; $<50 \mathrm{mmHg}$ in children aged $1-5$ years), jaundice, hematuria, bleeding manifestations, acute respiratory distress syndrome and death. The patients with a positive bacterial blood culture, leptospirosis and dengue, or any obvious bacterial or viral infections were excluded. Malaria parasite detection and load determination was done using Quantitative Buffy Coat (QBC) methodology using a fluorescent microscope. The speciation of the parasite was confirmed on peripheral smear. The parasite load on QBC was reported as $1+(<1$ parasite/HPF $), 2+(1-10$ parasites/HPF), 3+ (11 - 100 parasites/HPF $)$ and $4+(>100$ parasites/HPF). Commercial antisera were used for blood 


\section{International Journal of Science and Research (IJSR) \\ ISSN (Online): 2319-7064 \\ Index Copernicus Value (2013): 6.14 | Impact Factor (2015): 6.391}

group determination (tube and tile method) and mercury sphygmomanometer for blood pressure recording. Blood parameters including haemoglobin concentration were estimated by automated cell counters. Data analysis was done by Chi-square test and $\mathrm{P}$ value $<0.05$ was considered as statistically significant.

\section{Results}

In our study, malarial infection had a male preponderance, with $73 \%$ of the cases being males. Out of the 200 malaria positive patients, $86(43 \%)$ had blood group O, followed by $59(29.5 \%), 46(23 \%)$ and $9(4.5 \%)$ patients having blood group $\mathrm{A}, \mathrm{B}$ and $\mathrm{AB}$, respectively. P.vivax $(P v)$ infection was seen in 151 cases $(75.5 \%), P f$ in 29 cases $(14.5 \%)$ and the rest 20 cases $(10 \%)$ had mixed infection (Table 1$)$.

P.vivax infected cases most commonly had blood group $\mathrm{O}$ (43.7\%), followed by blood group $\mathrm{A}, \mathrm{B}$ and $\mathrm{AB}$ in $31.8 \%$, $20.5 \%$ and $4 \%$ cases. Out of the total Pf infected cases, the most common blood group was blood group O (44.8\%), followed by blood groups $\mathrm{B}, \mathrm{A}$ and $\mathrm{AB}$, in $37.9 \%, 13.8 \%$ and $3.4 \%$ cases, respectively. Among the cases having mixed infection, most cases had blood groups $\mathrm{O}$ and $\mathrm{A}(35 \%$ each), followed by $20 \%$ of blood group B and $10 \%$ of blood group AB. There was no statistical significance in the relationship between blood groups and the type of infection $\left(\mathrm{X}^{2}=8.035, \mathrm{P}=0.236\right)($ Table 1$)$.

In $35 \%$ of the cases, parasite load was $3+$, followed by $28.5 \%, 25.5 \%$ and $11 \%$ with parasite load of $2+, 4+$ and $1+$, respectively. Out of the cases that had a parasite load of $1+$; $40.9 \%$ had blood group O, 31.8\% and $27.3 \%$ cases had blood groups B and A, respectively. Among cases with parasite load of $2+, 45.6 \%$ had blood group $\mathrm{O} ; 33.3 \%$, $15.78 \%$ and $5.26 \%$ had blood groups $\mathrm{A}, \mathrm{B}$ and $\mathrm{AB}$ respectively. Out of the cases that had a parasite load of $3+$, $41.42 \%, 27.14 \%, 25.71 \%$ and $5.71 \%$ had blood groups O, B, $\mathrm{A}$ and $\mathrm{AB}$ respectively. Parasite load of $4+$ was seen in $43.13 \% .31 .37 \% .21 .56 \%$ and $3.92 \%$ had blood groups O, A, $\mathrm{B}$ and $\mathrm{AB}$, respectively. There was no statistical significance between blood group frequency and parasite load $\left(\mathrm{X}^{2}=\right.$ 4.806, $\mathrm{P}=0.851)($ Table 2$)$.

Among cases of blood group A, majority, that is $32.3 \%$ cases had a parasite load of $2+$, followed closely by a parasite load of $3+, 4+$ and $1+$ in $30.51 \%, 27.12 \%$ and $10.17 \%$ cases, respectively. For blood group B, parasite load of $3+, 4+, 1+$ and $2+$ in $41.3 \%, 23.91 \%, 19.57 \%$ and $15.22 \%$ cases, respectively. Parasite load of $3+, 4+, 2+$ and $1+$ in $44.44 \%, 33.33 \%, 22.22 \%$ and $11.11 \%$ cases in load group AB. Majority cases $(33.72 \%)$ of blood group $\mathrm{O}$ had a parasite load of $3+$, followed by $2+, 4+$ and $1+$ in $30.23 \%$, $25.5 \%$ and $10.47 \%$ cases, respectively (Table 2 ).

Out of the total number of malaria cases, $62(31 \%)$ cases had complications. In complicated cases, $37.09 \%$ cases had blood group $\mathrm{O}$, followed by $30.65 \%, 29.03 \%$ and $3.23 \%$ cases, had blood groups A, B and AB, respectively. Among the uncomplicated cases, the highest number of cases had blood group O (45.65\%), followed by $28.99 \%, 30.29 \%$ and $5.07 \%$ cases had blood group $\mathrm{A}, \mathrm{B}$ and $\mathrm{AB}$, respectively. Hence, blood group $\mathrm{O}$ had the highest number of both uncomplicated as well as complicated cases. There was no statistically significant relation between blood groups and the distribution of complicated and uncomplicated cases $\left(\mathrm{X}^{2}\right.$ $=2.514, \mathrm{P}=0.473)$ (Table 1).

Among complicated $P f$ malaria cases, $53.8 \%$ ( 7 cases) were of blood group B, 38.5\% (5 cases) of blood group O, and $7.7 \%$ ( 1 case) of blood group A (Table 1). No statistically significant relation was detected between complicated $P f$ cases and blood group types. $\left(\mathrm{X}^{2}=9.971, \mathrm{P}=0.126\right)$.

Jaundice was the most frequent $(18.5 \%$ cases $)$ complication, followed by hematuria, severe anemia and bleeding manifestation, in $9.5 \%, 4.5 \%$ and $2 \%$ cases, respectively. Cerebral malaria and death were recorded in 1 case $(0.5 \%)$ each. There was no statistically significant relationship between individual complications and blood groups.

Among complicated mixed malaria cases, 4 cases had blood group A, 2 cases had blood group $\mathrm{AB}$ and 1 case had blood group O. Blood group O (14.3\%) had a favorable outcome. Hence, there was a statistically significant relation between complicated mixed malaria cases and blood groups $\left(\mathrm{X}^{2}=\right.$ 15.131, $\mathrm{P}=0.019$ ) (Table 1 ).

Out of all the complicated cases, only $8(12.9 \%)$ cases had multiple complications. Multiple complications were seen in $16.7 \%$ of blood group B, $13 \%$ of blood group O and $10.5 \%$ of blood group A, cases. However, this wasn't a statistically significant $\left(\mathrm{X}^{2}=3.112 \mathrm{P}=0.795\right)$ finding. In $35.5 \%$ each of complicated cases, parasite load of $4+$ and $3+$, respectively. This was followed by $17.7 \%$ and $11.3 \%$ of complicated cases having parasite load was $2+$ and $1+$, respectively. Such a finding again didn't accrue any statistical significance $\left(\mathrm{X}^{2}\right.$ $=7.174, \mathrm{P}=0.067$ ) (Table 1). 


\section{International Journal of Science and Research (IJSR) \\ ISSN (Online): 2319-7064}

Index Copernicus Value (2013): 6.14 | Impact Factor (2015): 6.391

Table 1: Distribution of cases

\begin{tabular}{|c|c|c|c|c|c|c|c|c|c|c|c|c|c|c|c|c|}
\hline Blood groups & \multicolumn{3}{|c|}{ A } & \multicolumn{3}{|c|}{ B } & \multicolumn{3}{|c|}{$\mathrm{AB}$} & \multicolumn{3}{|c|}{$\mathrm{O}$} & \multicolumn{4}{|c|}{ Total } \\
\hline \multirow[t]{2}{*}{ Sex } & \multicolumn{2}{|l|}{ M } & $\mathrm{F}$ & \multicolumn{2}{|c|}{ M } & $\mathrm{F}$ & \multicolumn{2}{|c|}{ M } & $\mathrm{F}$ & \multicolumn{2}{|c|}{ M } & $\mathrm{F}$ & \multicolumn{2}{|c|}{ Males (M) } & \multicolumn{2}{|c|}{ Females $(F)$} \\
\hline & \multicolumn{2}{|c|}{41} & 18 & \multicolumn{2}{|c|}{36} & 10 & \multicolumn{2}{|c|}{8} & 1 & \multicolumn{2}{|c|}{61} & 25 & \multicolumn{2}{|c|}{$146(73 \%)$} & \multicolumn{2}{|c|}{$54(27 \%)$} \\
\hline \multirow{3}{*}{$\begin{array}{l}\text { Type of } \\
\text { infection }\end{array}$} & $\mathrm{V}$ & $\mathrm{F}$ & M & $\mathrm{V}$ & $\mathrm{F}$ & M & $\mathrm{V}$ & $\mathrm{F}$ & M & $\mathrm{V}$ & $\mathrm{F}$ & M & Vivax (V) & Fal & & Mixed (M) \\
\hline & 48 & 4 & 7 & 31 & 11 & 4 & 6 & 1 & 2 & 66 & 13 & 7 & $151(75.5 \%)$ & & & $20(10 \%)$ \\
\hline & \multicolumn{3}{|c|}{$59(29.5 \%)$} & \multicolumn{3}{|c|}{$46(23 \%)$} & \multicolumn{3}{|c|}{$9(4.5 \%)$} & \multicolumn{3}{|c|}{$86(43 \%)$} & \multicolumn{4}{|c|}{$200(100 \%)$} \\
\hline \multirow[t]{3}{*}{ Complicated cases } & $\mathrm{V}$ & $\mathrm{F}$ & M & $\mathrm{V}$ & $\mathrm{F}$ & M & $\mathrm{V}$ & $\mathrm{F}$ & M & V & $\mathrm{F}$ & M & \multirow{3}{*}{\multicolumn{2}{|c|}{$62(31 \%)$}} & \multirow{6}{*}{\multicolumn{2}{|c|}{$200(100 \%)$}} \\
\hline & 14 & 1 & 4 & 11 & 7 & 0 & 0 & 0 & 2 & 17 & 5 & 1 & & & & \\
\hline & \multicolumn{3}{|c|}{$19(30.65 \%)$} & \multicolumn{3}{|c|}{$18(29.03 \%)$} & \multicolumn{3}{|c|}{$2(3.23 \%)$} & \multicolumn{3}{|c|}{$23(37.09 \%)$} & & & & \\
\hline \multirow[t]{3}{*}{ Uncomplicated cases } & V & $\mathrm{F}$ & M & $\mathrm{V}$ & $\mathrm{F}$ & M & $\mathrm{V}$ & $\mathrm{F}$ & M & V & $\mathrm{F}$ & $\mathrm{M}$ & \multirow{3}{*}{\multicolumn{2}{|c|}{$138(69 \%)$}} & & \\
\hline & 34 & 3 & 3 & 20 & 4 & 4 & 6 & 1 & 0 & 49 & 8 & 6 & & & & \\
\hline & \multicolumn{3}{|c|}{$40(28.99 \%)$} & \multicolumn{3}{|c|}{$28(20.29 \%)$} & & & ) & & 45.6 & $\%)$ & & & & \\
\hline
\end{tabular}

Table 2: Parasite load vs blood group type

\begin{tabular}{|c|c|c|c|c|c|c|}
\hline \multicolumn{2}{|c|}{ Blood group } & A & B & AB & O & Total \\
\hline \multirow{2}{*}{$\begin{array}{c}\text { Parasite } \\
\text { load in } \\
\text { QBC }\end{array}$} & $1+$ & $6(27.27 \%)$ & $7(31.8 \%)$ & 0 & $9(40.9 \%)$ & $22(11 \%)$ \\
\cline { 2 - 7 } & $2+$ & $19(33.33 \%)$ & $9(15.78 \%)$ & $3(5.26 \%)$ & $26(45.6 \%)$ & $57(28.5 \%)$ \\
\cline { 2 - 7 } & $3+$ & $18(25.71 \%)$ & $19(27.14 \%)$ & $4(5.71 \%)$ & $29(41.42 \%)$ & $70(35 \%)$ \\
\cline { 2 - 7 } & $4+$ & $16(31.37 \%)$ & $11(21.56 \%)$ & $2(3.92 \%)$ & $22(43.13 \%)$ & $51(25.5 \%)$ \\
\hline
\end{tabular}

\section{Discussion}

In this study, there was no statistically significant relation between the incidence of malaria and blood groups, which was consistent with a study by Cavasini $\mathrm{CE}$ et $\mathrm{al}^{(6)}$. Contrarily, Zerihun $\mathrm{T}$ et al found that the incidence of $P f$ malaria is less in people with blood group $\mathrm{O}^{(7)}$.

Blood group $\mathrm{O}$, being the dominant blood type in uncomplicated malaria cases, was concordant with the other studies $^{(4)(5)}$. Majority of the complicated malaria cases were also of blood group $\mathrm{O}$ which correlated with findings by Martin et al ${ }^{(8)}$ but contradicted with others ${ }^{(4)(5)(9)(10)}$. In South India, blood group A constitutes only $18.85 \%$ of all blood groups, whereas blood groups $\mathrm{O}, \mathrm{B}$ and $\mathrm{AB}$ made $38.75 \%$, $32.69 \%$ and $5.27 \%$, respectively. Hence, the highest number of both uncomplicated as well as complicated cases in blood group $\mathrm{O}$, could be explained by the fact that blood group $\mathrm{O}$ is the most prevalent blood group in South India ${ }^{(11)}$. In the present study, maximum number of malaria cases had blood group $\mathrm{O}$ followed by blood group $\mathrm{A}$, though blood group B is commoner than blood group A.

Among blood group A patients, 32.2\% had complicated malaria and $67.8 \%$ had uncomplicated malaria, whereas among blood group O, 26.7\% had complicated malaria and $73.3 \%$ had uncomplicated malaria, consistent with the study of Lell et $\mathrm{al}^{(10)}$. In our study, however, blood group B had the highest proportion with $39.1 \%$ cases being complicated malaria cases. Therefore, blood group $\mathrm{O}$ is prone to less severe malaria though there is no statistically significant relation.
Previous studies have found a co-relation between severity of $P f$ malaria and blood groups, indicating favourable outcomes for blood group $\mathrm{O}^{(4)(5)(9)(10)}$. These authors also said that blood group A had a greater risk of developing severe $P f$ malaria. In our study, blood group B dominated the complicated $P f$ cases $(63.6 \%)$, coinciding with studies by Panda AK et $\mathrm{al}^{(12)}$, followed by blood group O. But this was not statistically significant. The number of complicated $P f$ cases in blood group B exceeded the cases having blood group A. These comparative differences in results could probably be explained by the fact that in the respective regions where they carried out their research blood group A was commoner than blood group B, and that their sample size was larger. Uneke CJ et al also found that blood group $\mathrm{O}$ had an advantage against severe $P f$ malaria $^{(2)}$. Blood group $\mathrm{O}$ is less prone to rosetting, in comparison to other blood groups, resulting in reduced complications in such individuals with $P f$ malaria. Rosetting is commoner in $P f$ than $P v$ and is a more established virulence factor of $P f$ infection $^{(2)(7)}$

However, there was a statistically significant relation between complicated mixed malaria cases and blood groups. Blood group A dominated the complicated mixed malaria category $(57.1 \%)$, followed by blood group $\mathrm{AB}$. Blood group $\mathrm{O}$ made only $14.3 \%$ of the total number of these cases. This means that blood group $\mathrm{O}$ does have a favourable outcome with complicated mixed malaria infections.

Human Duffy antigens act as receptors for $P v$ to invade human RBCs. The non-endemicity of $P v$ in Africa is attributed predominance of Duffy-negative blood group in 


\section{International Journal of Science and Research (IJSR) \\ ISSN (Online): 2319-7064 \\ Index Copernicus Value (2013): 6.14 | Impact Factor (2015): 6.391}

the population ${ }^{(13)}$. The $\mathrm{Ok}(\mathrm{a})$ blood group antigen basigin (BSG or CD147) is an erythrocyte receptor for the PfRh5 protein from Plasmodium falciparum and the PfRh5-BSG interaction is essential for erythrocyte invasion by $P f^{(14)}$.

Anopheles stephensi mosquito, which is the main malaria vector in Iran, southwest Asia, and India, were fed either artificially on $\mathrm{A} / \mathrm{B} / \mathrm{O} / \mathrm{AB}$ membrane blood feeders or directly on human volunteer hands and forearms of $\mathrm{A} / \mathrm{B} / \mathrm{O} / \mathrm{AB}$ groups, under lab conditions. Phenotype and genotype analyzes of 450-blood-fed mosquito specimens, revealed a significant blood preference of An. stephensi to AB group (40\%), followed by groups of A (24\%), B (21\%), and $\mathrm{O}(15 \%)$. High preference of An. stephensi to AB group might increase malaria infection and fatality in this blood group and resulted in low frequency of $\mathrm{AB}$ group in the residents of malaria endemic areas, suggesting that malaria vectors, like parasites may have selection pressure on human genotypes $^{(15)}$.

In conclusion, blood group $\mathrm{O}$ was the dominant blood type in both complicated and uncomplicated malaria cases. Blood group A patients were more prone to severe mixed malaria infections. Blood group $\mathrm{O}$ malaria cases had a favorable clinical outcome.

\section{Acknowledgements}

We offer our deepest thanks to Kasturba Medial College, Manipal University, Mangalore that provided technical support for the development and implementation of this study.

\section{Financial Support}

The study was supported by a research grant from Indian Council of Medical Research (ICMR), under STS-2011, awarded to Dr. Sharana Hegde.

\section{Conference Presentations}

This study was presented at the 19th International Student Congress of Medical Sciences (ISCOMS) at University Medical Center Groningen (UMCG), Groningen, The Netherlands on June 6th, 2012 by Dr. Sharana Hegde and was awarded the Best Paper award in the Genetics and Hematology category.

\section{References}

[1] World Health Organization. World Malaria report 2014. Geneva (Switzerland): World Health Organisation; 2014. Chapter 1, The public health challenge posed by malaria; p. 2 .

[2] Uneke CJ. Plasmodium falciparum malaria and ABO blood group: is there any relationship? Parasitol Res 2007; 100(4):759-65.

[3] Ockenhouse CF, Tegoshi T, Maeno Y, Benjamin C, Ho M, Kan KE et al. Human vascular endothelial cell adhesion receptors for Plasmodium falciparuminfected erythrocytes: roles for endothelial leukocyte adhesion molecule 1 and vascular cell adhesion molecule-1. J Exp Med 1992;176:1183-9.

[4] Pathirana SL, Alles HK, Bandara S, Phone-Kyaw M, Perera MK, Wickremasinghe AR et al. ABO-bloodgroup types and protection against severe, Plasmodium falciparum malaria. Ann Trop Med Parasitol 2005;99:119-24.

[5] Tekeste Z, Petros B. The ABO blood group and Plasmodium falciparum malaria in Awash, Metehara and Ziway areas, Ethiopia. Malaria J 2010;9:280.

[6] Cavasini CE, De Mattos LC, Alves RT, Couto AA, Calvosa VS, Domingos CR et al. Frequencies of $\mathrm{ABO}, \mathrm{MNSs}$, and Duffy phenotypes among blood donors and malaria patients from four Brazilian Amazon areas. Hum Biol 2006; 78(2):215-9.

[7] Zerihun T, Degarege A, Erko B. Association of ABO blood group and Plasmodium falciparum malaria in Dore Bafeno Area, Southern Ethiopia. Asian Pac J Trop Biomed 2011;1(4):289-94.

[8] Martin SK, Miller LH, Hicks CU, David-West A, Ugbode C, Deane M.Frequency of blood group antigens in Nigerian children with falciparum malaria. Trans Roy Soc Trop Med Hyg 1979;73:216-8.

[9] Fischer PR, Boone P.Short report: Severe malaria associated with blood group. Am J Trop Med Hyg 1998;58:122-3.

[10] Lell B, May J, Schmidt-Ott RJ, Lehman LG, Luckner D, Greve B, Matousek P, Schmid D, Herbich K, Mockenhaupt FP, Meyer CG, Bienzle U, Kremsner PG. The role of red blood cell polymorphisms in resistance and susceptibility to malaria. Clin Infect Dis 1999;28:794-9.

[11] Das PK, Nair SC, Harris VK, Rose D, Mammen JJ, Bose YN et al. Distribution of ABO and Rh-D blood groups among blood donors in a tertiary care centre in South India. Trop Doct 2001;31(1):47-8.

[12] Panda AK, Panda SK, Sahu AN, Tripathy R, Ravindran B, Das BK. Association of ABO blood group with severe falciparum malaria in adults: case control study and meta-analysis. Malar J 2011; 10:309.

[13] Ngassa Mbenda HG, Das A. Molecular evidence of Plasmodium vivax mono and mixed malaria parasite infections in Duffy-negative native Cameroonians. PLoS One 2014;9(8):e103262.

[14] Naka I, Patarapotikul J, Hananantachai H, Ohashi J. Lack of association between BSG polymorphisms and cerebral malaria. Jpn J Infect Dis 2014; 67(6):432-5.

[15] Anjomruz M, Oshaghi MA, Pourfatollah AA, Sedaghat MM, Raeisi A, Vatandoost $\mathrm{H}$ et al. Preferential feeding success of laboratory reared Anopheles stephensi mosquitoes according to ABO blood group status. Acta Trop 2014; 140:118-23.

\section{Author Contribution}

\section{Author 1: Sharana Hegde}

Data collection, manuscript preparation

\section{Author 2: Ruchi Sinha}

Concept design, final approval of the version to be published Author 3: Shrijeet Chakraborti

Review of literature, manuscript review, guarantor

Author 4: Lavnish Ojha

Data collection and analysis of abstract 